\title{
OPTIMASI KAPASITAS PRODUKSI UKM DENGAN GOAL PROGRAMMING
}

\author{
Welly Sugianto* \\ Dosen Prodi Teknik Industri Universitas Putera Batam \\ J1. Letjend. R. Soeprapto, Tembesi, Batam, Kepulauan Riau \\ *email: welly@puterabatam.ac.id
}

\begin{abstract}
This research's object is a small medium enterprise (SME) that engaged in the field of bakery production. Until now, they produce cakes and cookies. They sell products throughout the Batam area which includes (Tiban market, aviari market, mitra market and puja bahari market), shops, school canteens and so on. The SME targets several things such as profit per month, number of hours worked, number of overtime hours, machine utilities, labor utilities and so forth. Until now, the SME has not been able to reach the targets because the SME has not determined the production amount based on the appropriate calculation. The number of products made is determined only on an intuitive basis. Determination of the amount of production cannot be determined by the usual simplex method because the objective function in the usual simplex method contains a target. Problem solving is done by using goal programming. The results of the calculation analysis show that to achieve the optimal value, the SME must produce coconut root cookies, butter cookies, nastar cookies, snow princess cookies and peanut cookies respectively $11.89 \mathrm{~kg}, 22.43 \mathrm{~kg}, 24.96 \mathrm{~kg}$ , $1.97 \mathrm{~kg}$ and $0 \mathrm{~kg}$. Sensitivity analysis is carried out after there are changes in conditions that result in changes in the linear program matrix, so the number of products that must be made also changes which include coconut root cookies as much as $12.8 \mathrm{~kg}$, as much as $16.91 \mathrm{~kg}$ of butter cookies, nastar cookies as much as 25.7 and the last is $3.39 \mathrm{~kg}$ of nut cookies which in the initial calculation, nut cookies were not produced. The sensitivity analysis is not done by recalculation but rather by modifying the matrix and completing iteration with primal dual.
\end{abstract}

Keywords: SME, Goal programming, sensitivity analysis

\section{Pendahuluan}

Penelitian ini dilakukan pada sebuah UKM di kawasan tembesi yang bergerak di bidang produksi kue kering dan kue basah. Terdapat sekitar 5 varian kue yakni produk kue semprit akar kelapa, kue semprit, kue nastar, kue putri salju dan kue kacang. Seluruh produk dipasarkan di area batam yang antara lain adalah pasar, toko, kantin dan lain sebagainya.

UKM tersebut menargetkan beberapa hal seperti keuntungan per bulan, jumlah jam kerja, jumlah jam lembur, produk cacat, utilitas mesin, utilitas tenaga kerja dan lain sebagainya. UKM tersebut masih belum dapat mencapai seluruh targetnya karena jumlah produk yang diproduksi tidak dihitung dengan metode yang sesuai. Penentuan jumlah produk hanya dilakukan secara perkiraan namun tidak mempertimbangkan beberapa fungsi pembatas dan fungsi target serta penalti yang harus dibebankan ketika target tidak tercapai. Jumlah produk perlu diperhitungkan dengan seksama dan dengan menggunakan metode yang sesuai agar seluruh target dapat dicapai atau selisih antara target dan nilai realisasi dapat diminimumkan. Jika selisih antara target dan nilai realisasi sama dengan nol artinya UKM tersebut dapat mencapai target yang telah ditentukan.

Metode simpleks biasa tidak dapat diimplementasikan untuk menentukan hal ini karena metode simpleks merupakan metode pemrograman linier dengan fungsi tujuan yang tidak terbatas seperti menetukan nilai maksimum dan menentukan nilai minimum. Metode seimpleks biasa tidak memiliki fungsi tujuan dengan target. Metode yang akan digunakan adalah goal programming. Penelitian terdahulu juga menggunakan goal programming untuk menyelesaikan permasalahan yang serupa dengan permasalahan yang dihadapi oleh UKM Jovelyn. Untuk menyelesaikan masalah perencanaan produksi multi-dimensi seperti itu, metodologi goal programming yang fleksibel dan praktis dapat digunakan. Tujuan melaksanakan penelitian ini adalah untuk mengembangkan model goal programming ke situasi produksi UKM. Karena 
tingginya permintaan produk dan harga jual produk roti yang relatif terjangkau, perencanaan produksi perlu dioptimalkan agar dapat bersaing dengan toko roti lain di sekitarnya. Tujuan pengoptimalan adalah memaksimalkan laba penjualan harian, meminimalkan waktu kerja, dan memaksimalkan utilitas mesin yang digunakan dalam proses produksi. Metode tersebut tergolong efektif dan efisien (Hassan, Pazil, Idris, Razman, \& School, 2013).

Berdasarkan latar belakang tersebut, permasalahan mendasar yang akan ditentukan pemecahannya adalah penentuan kapasitas produksi dengan goal programming untuk 5 produk yakni produk kue semprit akar kelapa, kue semprit, kue nastar, kue putri salju dan kue kacang dan tujuan utamanya adalah untuk menentukan kapasitas produksi agar target pencapaian laba dapat tercapai.

\section{Landasan Teori}

Variabel dalam sistem simpleks dapat berbentuk lebih besar atau lebih kecil dan penyelesaiannya dapat menggunakan metode big $\mathrm{M}$ atau metode upper bound (Nadar, 2016). Permasalahan optimasi yang ada harus dikonversikan menjadi bentuk standar simpleks dengan ketentuan sebagai berikut (Yulia \& Singgih, 2012): (1) Semua fungsi pembatas atau fungsi konstrain yang berbentuk pertidaksamaan lebih kecil harus diubah dalam bentuk augmented dengan cara menambahkan slack; (2) Semua fungsi pembatas atau fungsi konstrain yang berbentuk pertidaksamaan lebih besar harus diubah dalam bentuk augmented dengan cara menambahkan variabel artifisial dan mengurangkan satu variabel surplus; (3) Semua fungsi pembatas atau fungsi konstrain yang berbentuk persamaan diubah menjadi bentuk augmented dengan cara menambahkan variabel artifisial; (4) Ruas kanan dari fungsi konstrain harus bernilai positif dan apabila tandanya negatif maka kedua ruas harus dikalikan dengan -1; (5) Fungsi objektif dalam bentuk maksimalisasi dan apabila dalam bentuk minimisasi maka fungsi objektif atau fungsi tujuan tersebut dikalikan dengan -1 dan fungsinya berubah menjadi maksimisasi. Bentuk standar programa linier dengan variabel keputusan sebanyak $n$ dan fungsi konstrain sebanyak m dijabarkan sebagai berikut (Bredström, Haugen, Olstad, \& Novotný, 2015):

$$
\operatorname{Max} Z=c_{1} x_{1}+\ldots \ldots . .+c_{n} x_{n}+0 s_{1} \ldots . .+0 s_{n}
$$

Persamaan tersebut disederhanakan dalam bentuk matematis sebagai berikut, di mana fungsi tujuan didefinisikan sebagai

$$
Z=\sum_{j=1}^{m} c_{j} x_{j}+\sum_{j=1}^{m} 0 s_{j}
$$

dengan fungsi konstrain didefinisikan sebagai

$$
\sum_{j=1}^{m} a_{i j} x_{j} s_{i}=b_{i}
$$

(Wahyudi, Anwar, \& Edijatno, 2014).

Metode simpleks adalah sebagai dasar utama dalam memahami serta melakukan goal programming. Seluruh iterasi dalam goal programming menggunakan urutan serta cara yang sama dengan metode simpleks (Yulia \& Singgih, 2012).

Goal programming merupakan metode yang hampir serupa dengan metode simpleks namun memiliki perbedaan mendasar di mana goal programming memiliki lebih dari satu fungsi tujuan selain itu goal programming memiliki nilai target pada fungsi tujuannya (Yahia-Berrouiguet \& Tissourassi, 2015).

Goal programming dapat dianggap sebagai cabang dari optimasi multi objektif yang dengan sendirinya merupakan bagian dari analisis keputusan multi-kriteria. goal programming adalah salah satu teknik pengambilan keputusan multi kriteria yang digunakan dalam optimalisasi beberapa tujuan objektif dengan meminimalkan penyimpangan untuk masing-masing tujuan dari target yang diinginkan (Orumie \& Ebong, 2014).

Secara umum, gagasan goal programming adalah untuk mengubah berbagai tujuan awal menjadi satu tujuan. goal programming hanya menghasilkan hasil yang efisien dan memuaskan daripada optimal. Hal ini terjadi karena, tidak biasa untuk selalu memuaskan setiap tujuan, sehingga goal programming berupaya mencapai tingkat memuaskan dari berbagai tujuan yang sedang dipertimbangkan (Yahia-Berrouiguet \& Tissourassi, 2015).

Fungsi tujuan umum didefinisikan sebagai:

$$
\operatorname{Min} Z=\sum_{i} w_{i}\left(d_{k}^{+}+d_{k}^{-}\right)
$$

di mana $\mathrm{i}=1,2, \ldots, \mathrm{m}$ dan fungsi konstrain umum didefinisikan sebagai

$$
\sum_{i} a_{i j}+d_{1}^{+}+d_{1}^{-}=b_{i}
$$

di mana $\mathrm{j}=1,2, \ldots, \mathrm{n}$ dan $\mathrm{i}=1,2, \ldots, \mathrm{m}$ (Wichapa \& Khokhajaikiat, 2017).

Persamaan matematis goal programming yang diberikan memiliki kesamaan dengan persamaan goal programming di atas. Terdapat beberapa ketentuan atau asumsi dasar yang berkaitan dengan goal programming yang antara lain adalah: (1) Additivity, asumsi aditivitas menyiratkan bahwa tingkat penalti untuk variabel penyimpangan yang tidak diinginkan dari tingkat target tidak tergantung pada tingkat variabel penyimpangan yang tidak diinginkan dari tujuan lain; (2) Proportionality, asumsi proporsi menyatakan bahwa nilai penalti untuk penyimpangan variabel dari nilai target besarnya sebanding dengan besarnya penyimpangan; (3) Divisibility, asumsi ini menyiratkan bahwa 
rentang nilai variabel berjenis real dan tidak dapat dipaksakan dalam bentuk bilangan bulat atau integer atau bahkan nilai diskrit; (4) Certainty, asumsi ini menyiratkan bahwa seluruh koefisien variabel baik di fungsi tujuan maupun di fungsi konstrain ditetapkan secara pasti(Wichapa \& Khokhajaikiat, 2017). Namun, penggunaan goal programming tidak selalu salah jika salah satu aksioma di atas tidak dipenuhi. Dalam kasus di mana aksioma keterbagian tidak berlaku, pemrograman bilangan bulat atau biner dapat dirumuskan. Ketika aksioma kepastian tidak berlaku, maka metode yang akan digunakan akan tergantung pada jenis koefisien yang ada ketidakpastian (Orumie \& Ebong, 2014).

Pemilihan komponen yang dapat diperbaiki untuk sistem seri paralel merupakan masalah optimasi multi-tujuan atau goal programming dan telah membahas dua model yang berbeda atau dua tujuan yang berbeda. Dalam model pertama, keandalan subsistem dianggap sebagai tujuan yang berbeda. Pada model kedua, biaya dan waktu yang dihabiskan untuk memperbaiki komponen dianggap sebagai dua tujuan yang berbeda. Masing-masing memiliki nilai target. Goal programming diusulkan untuk memperoleh komponen yang dapat diperbaiki untuk dua model di bawah beberapa kendala atau fungsi konstrain yang diberikan (Ali, Raghav, \& Bari, 2011).

Goal programming juga diimplementasikan pada proses perencanaan pembangunan BTS di mana dalam proses pembangunannya diusahakan membutuhkan seminimal mungkin perangkat keras jaringan tetapi dapat memenuhi semaksimal mungkin kapasitas trafik yang ada. Untuk melaksanakan perencanaan tersebut dibutuhkan optimasi jumlah dan trafik BTS dalam satu wilayah (Hakim, Anggraeni, \& Pribadi, 2012).

Perencanaan produksi yang tepat adalah syarat utama keberhasilan sistem produksi, yang mempertimbangkan berbagai keterbatasan sumber daya dunia nyata seperti anggaran, waktu, dan tenaga kerja. Model pemrograman linier dapat juga diterapkan pada bidang makanan dan minuman dalam rangka mengoptimalkan produksi harian dari usaha kecil dan menengah (UKM) dalam memproduksi muffin, cupcakes, brownies, cream puff, tart keju dan tart telur. Tiga tujuan yang dipertimbangkan adalah memaksimalkan keuntungan penjualan harian, meminimalkan waktu lembur, dan memaksimalkan utilitas mesin yang digunakan dalam produksi produk bakery. Hasil penyelesaian goal programming mengindikasikan bahwa UKM harus meninjau target laba sesuai dengan kebijakan lembur dan waktu penggunaan mesin (Hassan et al., 2013).

Perencanaan produksi adalah salah satu fungsi terpenting dalam proses manajemen produksi.
Perencanaan produksi dalam rentang waktu menengah disebut sebagai perencanaan produksi agregat. Perencanaan produksi agregat adalah kegiatan perencanaan tingkat atas yang penting dalam sistem manajemen produksi. Model perencanaan produksi agregat selama satu tahun ditentukan dengan pendekatan goal programming. Temuan mengungkapkan bahwa goal programming dengan multi tujuan menghasilkan solusi yang lebih tepat daripada pemrograman linier dengan hanya satu tujuan (Farzam Rad \& Shirouyehzad, 2014).

Goal programming digunakan untuk mengoptimalkan alokasi waktu dan biaya pada manajemen proyek. Metode penyelesaian goal programming dilakukan secara bertahap atau preemptive (Yahia-Berrouiguet \& Tissourassi, 2015).

Masalah memilih segmen pelanggan sasaran, mempertimbangkan berbagai prioritas dan kendala anggaran, dapat dimodelkan sebagai masalah optimisasi multi-tujuan dengan sasaran fleksibel dan prioritas berbeda, saling ketergantungan dan kendala sumber daya. Tujuan utamanya adalah untuk menunjukkan penggunaan goal programming untuk mengatasi tantangan ini. (Asllani \& Lari, 2015).

Goal programming, dikenal juga sebagai optimisasi multi-kriteria atau multi-atribut, adalah proses mengoptimalkan secara bersamaan dua atau lebih tujuan yang saling bertentangan. Pemrograman multiobjek baru yang disebut pemrograman multiobjek tidak pasti yang merupakan jenis pemrograman multiobjek yang melibatkan variabel tidak pasti. Beberapa properti matematika juga dieksplorasi. Selain itu, goal programming yang tidak pasti diperkenalkan sebagai metode kompromi untuk menyelesaikan model pemrograman multiobjek yang tidak pasti (Liu \& Chen, 2015).

Non linear goal programming juga digunakan untuk memecahkan masalah perencanaan kapasitas penerimaan di universitas. Banyak faktor perencanaan kapasitas penerimaan universitas telah dipertimbangkan di antaranya adalah jumlah siswa yang diterima di tahun-tahun terakhir, total populasi di negara, jumlah lulusan dari sekolah menengah, rasio yang diinginkan untuk spesialisasi tertentu, rasio jumlah dosen mahasiswa, dan jumlah lulusan sebelumnya. Permasalahan tersebut diselesaikan dengan goal programming (El-quliti et al., 2015).

Goal programming juga digunakan dalam estimasi keuangan suatu organisasi atau institusi dalam mencapai tujuan lembaga secara ekonomi dan finansial. (Jyoti \& Mannan, 2016).

Proses pemilihan pemasok telah mengalami perubahan signifikan selama 20 tahun terakhir. Perubahan tersebut terjadi pada peningkatan garis 
panduan kualitas, peningkatan keandalan, pengurangan biaya produk dan peningkatan kemampuan teknis. Seleksi rantai suplai pemasok adalah masalah multi-objektif yang melibatkan kriteria kuantitatif dan kualitatif. Selama bertahun-tahun, sejumlah pendekatan kuantitatif telah diterapkan untuk masalah pemilihan pemasok. Aplikasi komprehensif goal programming dengan alat perangkat lunak untuk kasus situasi nyata disajikan bersama dengan perubahan prioritas tujuan ke rantai suplai pemasok terbaik dengan biaya optimal (Raghavulu, Nynaru, Ch, \& Satya, 2016).

Salah satu masalah keputusan yang paling sulit dalam pemasaran adalah penentuan alokasi penjualan yang optimal. goal programming digunakan untuk resolusi kebijakan penjualan yang mencakup semua lini produk eksklusif yang dijual di berbagai wilayah penjualan (Reddy, Sunitha, \& Reddy, 2017).

Model diet DASH (Dietary Approaches to Stop Hypertension) Linear Programming untuk penderita hipertensi sebelumnya telah dirumuskan dan rencana diet biaya harian minimum yang memenuhi tingkat asupan nutrisi DASH yang dapat ditoleransi untuk $1500 \mathrm{mg}$ sehari. Tingkat natrium dan kadar kalori harian yang berbeda diperoleh dengan menggunakan sampel makanan dari bagan rencana makan diet DASH. Model diet DASH Weighted Goal programming yang meminimalkan biaya harian dari rencana makan DASH serta penyimpangan dari kandungan nutrisi diet dari tingkat asupan makanan DASH diet yang mudah disajikan (Iwuji \& Agwu, 2017).

Model optimisasi goal programming dikembangkan untuk menentukan alokasi optimal produksi baja cair di setiap EAF, untuk memenuhi permintaan dalam 3 periode dan tujuan perusahaan, yaitu memaksimalkan volume produksi, meminimalkan biaya bahan baku, meminimalkan pemeliharaan biaya, memaksimalkan pendapatan penjualan, dan memaksimalkan kapasitas produksi (Hapsari \& Rosyidi, 2017).

Penerapan goal programming sangat luas dan dapat diimplementasikan pada penganggaran modal dan pada penentuan beberapa proyek yang saling eksklusif satu sama lain dengan memberikan nilai sekarang dari pengeluaran untuk periode tersebut dan memberikan nilai sekarang dari proposal investasi industri skala besar. Suatu pendekatan menggunakan goal programming digambarkan sebagai alternatif praktis yang mungkin. goal programming merupakan metode untuk mengambil keputusan dengan memperhatikan fungsi tujuan yang berbentuk target. Saat ini goal programming telah dikembangkan lebih lanjut dengan menggunakan matriks sehingga perhitungan menjadi lebih sederhana. (Kumar, Babu, \& Kumar, 2018).

\section{Metode Penelitian}

Metode penelitian meliputi beberapa hal antara lain adalah (1) Mengidentifikasi beberapa fungsi tujuan serta menentukan target dari fungsi tujuan; (2) Menentukan besar denda atau penalti sebagai akibat dari target yang tidak tercapai baik lebih besar maupun lebih kecil (3) Menentukan prioritas penyelesaian; (4) Pada fungsi konstrain, untuk fungsi pembatas dengan tanda lebih kecil, tambahkan variabel slack; (5) Pada fungsi konstrain, untuk fungsi pembatas dengan tanda lebih besar, kurangi dulu dengan variabel surplus, kemudian tambahkan dengan variabel artifisial; (6) Pada fungsi konstrain, untuk fungsi pembatas dengan tanda sama dengan, ditambahkan variabel artifisial; (7) Pada fungsi tujuan, ditambahkan variabel slack (dengan koefisien 0), variabel surplus (dengan koefisien 0), dan variabel artifisial (dengan koefisien -M); (8) Pada fungsi konstrain ditambahkan variabel. Langkah berikutnya adalah menyelesaikan programa linier melalui tabulasi dengan iterasi sebagai berikut : (1) Melakukan OBE atau operasi basis dasar agar dapat diperoleh jawaban optimal; (2) Pada tahap awal, seluruh variabel (selain variabel slack dan artifisial) yang ada di fungsi tujuan merupakan variabel non basic yang nilainya adalah nol; (3) Tentukan variabel basic masuk atau entering basic variable (berdasarkan koefisien $\mathrm{Zj}$ tersebesar); (4) Tentukan variabel non basic keluar atau leaving non basic variable (rasio yang terkecil antara ruas kanan dengan koefisien variabel basic masuk); (5) Tentukan kolom pivot (ubah nilai non basic variabel menjadi 1); (6) Lakukan operasi baris elementer berdasarkan pivot ini untuk baris lainnya termasuk baris $\mathrm{Zj}-$ $\mathrm{Cj}$. Seluruh baris pivot yang lain selain variabel non basic nilainya adalah nol dan (7) Proses iterasi dihentikan, apabila semua nilai pada $\mathrm{Zj}-$ $\mathrm{Cj} \geq 0$. Analisis sesitivitas dilakukan dengan menggunakan matriks sebagai berikut:

$$
\begin{gathered}
{\left[\begin{array}{ccc}
1 & -C & 0 \\
0 & A & I
\end{array}\right]\left[\begin{array}{c}
Z \\
x \\
x_{s}
\end{array}\right]=\left[\begin{array}{l}
k \\
b
\end{array}\right]} \\
{\left[\begin{array}{ccc}
-1 & -C_{b} B^{-1} A+C & -C_{b} B^{-1} \\
0 & B^{-1} A & B^{-1}
\end{array}\right]=\left[\begin{array}{c}
-k-C_{b} B^{-1} b \\
B^{-1} b
\end{array}\right]}
\end{gathered}
$$

Keterangan :

A = Matriks koefisien fungsi pembatas

$\mathrm{I}=$ Matriks identitas

$\mathrm{C}=$ Koefisien fungsi tujuan

$\mathrm{k}=$ Nilai ruas kiri dari fungsi tujuan

$\mathrm{b}=$ Nilai ruas kanan dari fungsi tujuan

$\mathrm{x}=$ variabel kapasitas produksi

$\mathrm{x}_{\mathrm{s}}=$ variabel slack 


\section{Hasil dan Pembahasan}

Berdasarkan pada data biaya produksi dan harga jual produk maka dibuat persamaan tujuan sebagai berikut :

Total keuntungan $=10$ ribu +5 ribu +20 ribu

+7 ribu +10 ribu $=$ Rp .750 .000

$\mathrm{X}_{1}=$ Jumlah produk kue semprit akar kelapa dalam satuan kilogram

$\mathrm{X}_{2}=$ Jumlah produk kue semprit dalam satuan kilogram

$\mathrm{X}_{3}=$ Jumlah produk kue nastar dalam satuan kilogram

$\mathrm{X}_{4}=$ Jumlah produk kue kacang dalam satuan kilogram

$\mathrm{X}_{5}=$ Jumlah produk kue putri salju dalam satuan kilogram

Selanjutnya adalah penentuan persamaan pembatas dengan menggunakan data biaya dan kapasitas.

Jam kerja $=1,7 \mathrm{X}_{1}+3,57 \mathrm{X}_{2}+1,27 \mathrm{X}_{3}+$

$3,43 \mathrm{X}_{4}+2,75 \mathrm{X}_{5}=50$

Jam Tenaga kerja $=4583 \mathrm{X}_{1}+7857 \mathrm{X}_{2}+$ $2340 X_{3}+6875 X_{4}+5500 X_{5}=R p 300$ ribu

Bahan baku $=27000 \mathrm{X}_{1}+24642 \mathrm{X}_{2}+$

$40638 \mathrm{X}_{3}+19637 \mathrm{X}_{4}+56700 \mathrm{X}_{5}=2 \mathrm{juta}$

Total wajan $=3 \mathrm{X}_{1}+\mathrm{X}_{2}+2 \mathrm{X}_{3}+\mathrm{X}_{4}+\mathrm{X}_{5}$ $=110$ buah

Terdapat 5 persamaan goal programming. Persamaan goal programming total keuntungan bersifat lower, one side goal di mana keuntungan minimum per hari adalah sebesar Rp750.000. Persamaan goal programming yang lain bersifat two side di mana iterasi dilakukan untuk memenuhi persamaan tersebut dari dua sisi dan tidak boleh meleset dari dua sisi. Selanjutnya adalah menambahkan variabel artifisial y+ dan y-. Sifat variabel artifisial adalah sebagai berikut:

$$
\begin{aligned}
y_{j}^{+} & =\left\{\begin{array}{l}
y_{j}, \text { jika } y_{j} \geq 0 \\
0, \text { jika } y_{j}<0
\end{array}\right. \\
y_{j}^{-} & =\left\{\begin{array}{l}
\left|y_{j}\right|, \text { jika } y_{j} \leq 0 \\
0, \text { jika } y_{j}>0
\end{array}\right.
\end{aligned}
$$

Persyaratan adalah jika nilai positif maka nilai positif. Persyaratan adalah jika bernilai positif maka nilai adalah negatif. Kedua variabel artifisial tersebut biasanya digunakan pada programa linier dengan variabel yang tidak jelas tandanya sehingga bisa bernilai negative atau positif. Pada goal programming, variabel artifisial merupakan variabel yang mendefinisikan selisih antara pencapaian dan target. Jika variabel artifisial ditambahkan pada kelima persamaan Goal programming di atas maka persamaan tersebut akan berubah menjadi:

$10.000 x_{1}+5.000 x_{2}+20.000 x_{3}+7.000 x_{4}+10.000 x_{5}-\left(y_{1}^{+}-y_{1}^{-}\right)=750.000$

$$
1,7 x_{1}+3,57 x_{2}+1,27 x_{3}+3,43 x_{4}+2,75 x_{5}-\left(y_{2}^{+}-y_{2}^{-}\right)=50
$$

$4.583 x_{1}+7.857 x_{2}+2340 x_{3}+6875 x_{4}+5.500 x_{5}-\left(y_{3}^{+}-y_{3}^{-}\right)=300.000$

$27.000 x_{1}+24.642 x_{2}+40638 x_{3}+19637 x_{4}+56.700 x_{5}-\left(y_{4}^{+}-y_{4}^{-}\right)=2.000 .000$

$$
3 x_{1}+x_{2}+2 x_{3}+x_{4}+x_{5}-\left(y_{5}^{+}-y_{5}^{-}\right)=110
$$

Selanjutnya adalah penentuan persamaan penalti di mana goal programming bertujuan untuk meminimumkan fungsi penalti sebagai berikut:

$$
\operatorname{Min}\left(\begin{array}{l}
Z^{*}=30 \text { ribu. } y_{1}^{-}+20 \text { ribu. } y_{2}^{+}+30 \text { ribu. } y_{2}^{-} \\
+20 \text { ribu. } y_{3}^{+}+30 \text { ribu. } y_{3}^{-}+30 \text { ribu } y_{4}^{+}+20 \text { ribu. } y_{4}^{-} \\
+40 \text { ribu. } y_{5}^{+}+50 \text { ribu. } y_{5}^{-}
\end{array}\right)
$$

Untuk memudahkan perhitungan maka persaman tujuan tersebut disederhanakan dengan membagi kedua ruas persamaan dengan 10 ribu sehingga didapatkan persamaan sebagai berikut:

$$
\operatorname{Min}\left(\begin{array}{l}
10^{-4} \cdot Z^{*}=3 y_{1}^{-}+2 y_{2}^{+}+3 y_{2}^{-}+2 y_{3}^{+} \\
+3 y_{3}^{-}+3 y_{4}^{+}+2 y_{4}^{-}+4 y_{5}^{+}+5 y_{5}^{-}=0
\end{array}\right)
$$

Ruas kiri diubah menjadi $\mathrm{Z}$ sehingga menjadi:

$$
\operatorname{Min}\left(\begin{array}{l}
Z=3 y_{1}^{-}+2 y_{2}^{+}+3 y_{2}^{-}+2 y_{3}^{+} \\
+3 y_{3}^{-}+3 y_{4}^{+}+2 y_{4}^{-}+4 y_{5}^{+}+5 y_{5}^{-}=0
\end{array}\right)
$$

Supaya persamaan tersebut dapat dikerjakan dengan metode simpleks maka persamaan tersebut harus diubah dalam bentuk maksimalisasi menjadi:

$$
\operatorname{Max}\left(\begin{array}{l}
-Z+3 y_{1}^{-}+2 y_{2}^{+}+3 y_{2}^{-}+2 y_{3}^{+} \\
+3 y_{3}^{-}+3 y_{4}^{+}+2 y_{4}^{-}+4 y_{5}^{+}+5 y_{5}^{-}=0
\end{array}\right)
$$

Seluruh variabel artifisial pada persamaan di atas merupakan variabel basic sehingga persamaan tujuan penalti harus diubah sedemikian rupa sehingga seluruh koefisien variabel basic pada persamaan tujuan bernilai 0 . Hal ini dilakukan dengan cara mengeleminasikan persamaan fungsi tujuan dengan persamaan konstrain sebagai berikut:

$$
\begin{aligned}
& -Z+3 y_{1}^{-}+2 y_{2}^{+}+3 y_{2}^{-}+2 y_{3}^{+}+3 y_{3}^{-}+3 y_{4}^{+}+2 y_{4}^{-} \\
& +4 y_{5}^{+}+5 z_{5}^{-}=0 \\
& \left(\begin{array}{l}
10.000 x_{1}+5.000 x_{2}+20.000 x_{3}+7.000 x_{4}+ \\
10.000 x_{5}-\left(y_{1}^{+}-y_{1}^{-}\right)=750.000
\end{array}\right) \times 3 \\
& \left(\begin{array}{l}
1,7 x_{1}+3,57 x_{2}+1,27 x_{3}+3,43 x_{4}+2,75 x_{5} \\
-\left(y_{2}^{+}-y_{2}^{-}\right)=50
\end{array}\right) \times 3 \\
& \left(\begin{array}{l}
4.583 x_{1}+7.857 x_{2}+2340 x_{3}+6875 x_{4}+ \\
5.500 x_{5}-\left(y_{3}^{+}-y_{3}^{-}\right)=300.000
\end{array}\right) \times 3 \\
& \left(\begin{array}{l}
27.000 x_{1}+24.642 x_{2}+40638 x_{3}+19637 x_{4} \\
+56.700 x_{5}-\left(y_{4}^{+}-y_{4}^{-}\right)=2.000 .000
\end{array}\right) \times 2 \\
& \left(3 x_{1}+x_{2}+2 x_{3}+x_{4}+x_{5}-\left(y_{5}^{+}-y_{5}^{-}\right)=110\right) \times 5
\end{aligned}
$$

Eliminasi dilakukan sehingga persamaan fungsi penalti berubah menjadi

$$
\begin{aligned}
& -Z-97.769,1 x_{1}-87.870,71 x_{2}-148.309,81 x_{3} \\
& -80.914,29 x_{4}-159.913,25 x_{5}+3 y_{1}^{+}+0 y_{1}^{-}+5 y_{2}^{+} \\
& +0 y_{2}^{-}+5 y_{3}^{+}+0 y_{3}^{-}+5 y_{4}^{+}+0 y_{4}^{-}+9 y_{5}^{+}+0 z_{5}^{-} \\
& =-7.150 .700
\end{aligned}
$$

Langkah berikutnya adalah melakukan iterasi : 
Tabel 1. Iterasi pertama

\begin{tabular}{|c|c|c|c|c|c|c|c|c|c|c|c|c|c|c|c|c|c|}
\hline & $z$ & $\mathrm{x} 1$ & $x 2$ & $x 3$ & $x 4$ & x5 & $\mathrm{y} 1+$ & y1- & $y 2+$ & y2- & y3+ & y3- & y4+ & y4- & y5+ & y5- & $\mathbf{R}$ \\
\hline & -1 & -97769.1 & -87870.7 & -148310 & -80914.3 & -159913 & 3 & 0 & 5 & 0 & 5 & 0 & 5 & 0 & 9 & 0 & 7150700 \\
\hline y1- & 0 & 10000 & 5000 & 20000 & 7000 & 10000 & -1 & 1 & 0 & 0 & 0 & 0 & 0 & 0 & 0 & 0 & 750000 \\
\hline y2- & 0 & 1.7 & 3.57 & 1.27 & 3.43 & 2.75 & 0 & 0 & -1 & 1 & 0 & 0 & 0 & 0 & 0 & 0 & 50 \\
\hline y3- & 0 & 4583 & 7857 & 2340 & 6875 & 5500 & 0 & 0 & 0 & 0 & -1 & 1 & 0 & 0 & 0 & 0 & 300000 \\
\hline y4- & 0 & 27000 & 24642 & 40638 & 19637 & 56700 & 0 & 0 & 0 & 0 & 0 & 0 & -1 & 1 & 0 & 0 & 2000000 \\
\hline y5- & 0 & 3 & 1 & 2 & 1 & 1 & 0 & 0 & 0 & 0 & 0 & 0 & 0 & 0 & -1 & 1 & 110 \\
\hline
\end{tabular}

Tabel 2. Iterasi terakhir

\begin{tabular}{|c|c|c|c|c|c|c|c|c|c|c|c|c|c|c|c|c|c|}
\hline & $y$ & $x 1$ & $x 2$ & x3 & $x 4$ & $x 5$ & y1+ & y1- & y2+ & y2- & y3+ & y3- & y4+ & y4- & y5t & y5- & $\mathbf{R}$ \\
\hline & -1 & 0 & 0 & 0 & 1 & 0 & 0 & 3 & 0 & 5 & 2 & 3 & 3 & 2 & 3 & 6 & -174.84 \\
\hline$x 3$ & 0 & 0 & 0 & 1 & 0 & 0 & 0 & 0 & 0 & 0 & 0 & 0 & 0 & 0 & 0 & 0 & 24.96 \\
\hline$x 5$ & 0 & 0 & 0 & 0 & 0 & 1 & 0 & 0 & 0 & 0 & 0 & 0 & 0 & 0 & 0 & 0 & 1.97 \\
\hline$\times 2$ & 0 & 0 & 1 & 0 & 1 & 0 & 0 & 0 & 0 & 0 & 0 & 0 & 0 & 0 & 0 & 0 & 22.43 \\
\hline y2+ & 0 & 0 & 0 & 0 & 0 & 0 & 0 & 0 & 1 & -1 & 0 & 0 & 0 & 0 & 0 & 0 & 87.42 \\
\hline $\mathrm{x1}$ & 0 & 1 & 0 & 0 & 0 & 0 & 0 & 0 & 0 & 0 & 0 & 0 & 0 & 0 & -1 & 1 & 11.89 \\
\hline
\end{tabular}

Hasil perhitungan menunjukkan bahwa untuk mencapai nilai optimal maka UKM Jovelyn harus memproduksi produk dengan jumlah yang ditunjukkan pada Tabel 2. Produk kue semprit akar kelapa harus diproduksi sejumlah $11,89 \mathrm{~kg}$. Produk kue semprit harus diproduksi sebanyak $22,43 \mathrm{~kg}$. Produk kue nastar harus diproduksi sebanyak $24,96 \mathrm{~kg}$. Produk kue putri salju harus diproduksi sebanyak $1,97 \mathrm{~kg}$. Produk kue kacang tidak diproduksi. Selanjutnya dilakukan analisis sensitivitas berdasarkan pada perubahan biaya bahan baku sebagai berikut:

$\bar{A}=\left[\begin{array}{cccccccccc}10.000 & 5.000 & 20.000 & 7.000 & 10.000 & -1 & 0 & 0 & 0 & 0 \\ 1,7 & 3,57 & 1,27 & 3,43 & 2,75 & 0 & -1 & 0 & 0 & 0 \\ 5.000 & 8.571 & 2.553 & 7.500 & 6.000 & 0 & 0 & -1 & 0 & 0 \\ 28.833 & 25.928 & 43.617 & 21.262 & 61.065 & 0 & 0 & 0 & -1 & 0 \\ 3 & 1 & 2 & 1 & 1 & 0 & 0 & 0 & 0 & -1\end{array}\right]$

Dan matriks $-C_{b} B^{-1}=\left[\begin{array}{lllll}3 & 5 & 3 & 2 & 5,52\end{array}\right]$.

Matriks invers $B$ yang digunakan bukan dengan pembulatan melainkan 5 angka dibelakang koma sehingga matriks invers B adalah:

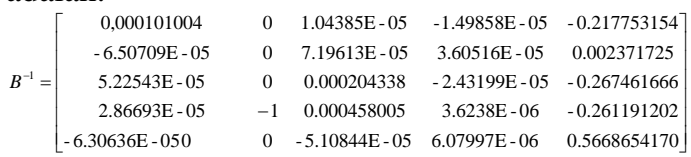

Vektor C tidak berubah yakni:

$C=\left[\begin{array}{llllllllll}-97769.1 & -87870.71 & -148309.8 & -80914.29 & -159913.3 & 3 & 5 & 5 & 5 & 9\end{array}\right]$
Berdasarkan matriks A yang baru maka ditentukan matriks yang lain berdasarkan kedua matriks berikut ini yakni matriks vector $-C_{b} B^{-1} \bar{A}+\bar{C}, \quad-k+C_{b} B^{-1} \bar{b}, \quad B^{-1} \bar{A} \quad$ dan $B^{-1} b$. Selanjutnya adalah mencari hasil perhitungan vector $-C_{b} B^{-1} \bar{A}+\bar{C}$.

$-C_{b} B^{-1} \bar{A}+\bar{C}=\left[\begin{array}{lllll}2,999943 & 5 & 2,999084 & 1,999993 & 5,522382\end{array}\right] \times$

$\left[\begin{array}{llllllllll}10.000 & 5.000 & 20.000 & 7.000 & 10.000-1 & 0 & 0 & 0 & 0\end{array}\right]$

$\begin{array}{llllllllll}1,7 & 3,57 & 1,27 & 3,43 & 2,75 & 0 & -1 & 0 & 0 & 0\end{array}$

$\begin{array}{lllllllllll}5.000 & 8.571 & 2.553 & 7.500 & 6.000 & 0 & 0 & -1 & 0 & 0 & +\end{array}$

$\begin{array}{llllllllll}28.833 & 25.928 & 43.617 & 21.262 & 61.065 & 0 & 0 & 0 & -1 & 0\end{array}$

$\left[\begin{array}{llllllllll}3 & 1 & 2 & 1 & 1 & 0 & 0 & 0 & 0 & -1\end{array}\right]$

$\left[\begin{array}{llllllllll}-97769.1 & -87870.71 & -148309.8 & -80914.29 & -159913.3 & 3 & 5 & 5 & 5 & 9\end{array}\right]$

Selanjutnya adalah menghitung nilai matriks $-k-C_{b} B^{-1} \bar{b}$ sebagai berikut :

$$
\begin{aligned}
& -k+C_{b} B^{-1} \bar{b}=-(-7.150 .700)- \\
& {\left[\begin{array}{lllll}
3 & 5 & 3 & 2 & 5,52
\end{array}\right]\left[\begin{array}{c}
750.000 \\
50 \\
300.000 \\
2.000 .000 \\
110
\end{array}\right]=-174.84}
\end{aligned}
$$

Kemudian dihitung matriks $B^{-1} \bar{A}$ sebagai berikut : 


$B^{-1} \bar{A}==\left[\begin{array}{ccccc}0,000101004 & 0 & 1.04385 \mathrm{E}-05 & -1.49858 \mathrm{E}-05 & -0.217753154 \\ -6.50709 \mathrm{E}-05 & 0 & 7.19613 \mathrm{E}-05 & 3.60516 \mathrm{E}-05 & 0.002371725 \\ 5.22543 \mathrm{E}-05 & 0 & 0.000204338 & -2.43199 \mathrm{E}-05 & -0.267461666 \\ 2.86693 \mathrm{E}-05 & -1 & 0.000458005 & 3.6238 \mathrm{E}-06 & -0.261191202 \\ -6.30636 \mathrm{E}-050 & 0 & -5.10844 \mathrm{E}-05 & 6.07997 \mathrm{E}-06 & 0.5668654170\end{array}\right]$

$\left[\begin{array}{cccccccccc}10.000 & 5.000 & 20.000 & 7.000 & 10.000 & -1 & 0 & 0 & 0 & 0 \\ 1,7 & 3,57 & 1,27 & 3,43 & 2,75 & 0 & -1 & 0 & 0 & 0 \\ 5.000 & 8.571 & 2.553 & 7.500 & 6.000 & 0 & 0 & -1 & 0 & 0 \\ 28.833 & 25.928 & 43.617 & 21.262 & 61.065 & 0 & 0 & 0 & -1 & 0 \\ 3 & 1 & 2 & 1 & 1 & 0 & 0 & 0 & 0 & -1\end{array}\right]$

$\left[\begin{array}{lllllll}-0.023116141 & -0.011818683 & 0.957580682 & 0.248932828 & -0.060193804 & -0.000101 & 0\end{array}\right.$ $\begin{array}{lllllll}0.03607467 & -0.005018066 & 0.092069898 & -0.22630596 & 1.121384485 & 6.50709 \mathrm{E}-05 & 0\end{array}$

$=\begin{array}{llllllll}0.040630447 & 1.114621729 & -0.028925049 & 1.113761217 & -0.003987509 & -5.2254 \mathrm{E}-05 & 0\end{array}$ $\begin{array}{llllllll}0.197630598 & 0.33167593 & 0.108350407 & 0.021582327 & 0.244820489 & -2.8669 \mathrm{E}-05 & 1\end{array}$ $\left[\begin{array}{llllllll}0.989842388 & -0.028655432 & 0.007231262 & -0.128440304 & 0.000996877 & 6.30636 \mathrm{E}-05 & 0\end{array}\right.$

$-1.0438 \mathrm{E}-05 \quad 1.49858 \mathrm{E}-05 \quad 0.217753$ $7.19613 \mathrm{E}-05-3.60516 \mathrm{E}-05-0.00237$ $-0.000204342 .43199 \mathrm{E}-05 \quad 0.267462$ $-0.00045801-3.6238 \mathrm{E}-06 \quad 0.261191$ $5.10844 \mathrm{E}-05-6.07997 \mathrm{E}-06-0.56687$

Hasil perkalian $B^{-1} \bar{A}$ menunjukkan bahwa perlu dilakukan eleminasi gauss supaya matriks menjadi sesuai dan optimal. Hasil perkalian matriks di atas dimasukkan dalam tabel simpleks sebagai berikut:

Tabel 3. Revisi matriks

\begin{tabular}{|c|c|c|c|c|c|c|c|c|c|c|c|c|c|c|c|c|c|}
\hline & & $\mathrm{x} 1$ & $x 2$ & $x 3$ & $x 4$ & $x 5$ & y1+ & $y 2+$ & y3+ & y4+ & y5+ & y1- & y2- & y3- & y4- & y5- & $\mathbf{R}$ \\
\hline & $\begin{array}{l}- \\
1\end{array}$ & $\begin{array}{c}4916.6 \\
0\end{array}$ & $\begin{array}{c}4713.3 \\
4\end{array}$ & $\begin{array}{c}6596.7 \\
8\end{array}$ & $\begin{array}{c}5124.9 \\
6\end{array}$ & $\begin{array}{c}10229.5 \\
1\end{array}$ & $\begin{array}{c}0.0 \\
0\end{array}$ & $\begin{array}{c}0.0 \\
0\end{array}$ & $\begin{array}{c}2.0 \\
0\end{array}$ & $\begin{array}{c}3.0 \\
0\end{array}$ & 3.48 & $\begin{array}{c}3.0 \\
0\end{array}$ & 5.00 & $\begin{array}{c}3.0 \\
0\end{array}$ & $\begin{array}{c}2.0 \\
0\end{array}$ & 5.52 & $\begin{array}{c}- \\
174.84\end{array}$ \\
\hline$x 3$ & 0 & -0.02 & -0.01 & 0.96 & 0.25 & -0.06 & $\begin{array}{c}0.0 \\
0\end{array}$ & $\begin{array}{c}0.0 \\
0\end{array}$ & $\begin{array}{c}0.0 \\
0\end{array}$ & $\begin{array}{c}0.0 \\
0\end{array}$ & 0.22 & $\begin{array}{c}0.0 \\
0\end{array}$ & 0.00 & $\begin{array}{c}0.0 \\
0\end{array}$ & $\begin{array}{c}0.0 \\
0\end{array}$ & $\begin{array}{c}- \\
0.22\end{array}$ & 24.96 \\
\hline$x 2$ & 0 & 0.04 & 1.11 & -0.03 & 1.11 & 0.00 & $\begin{array}{c}0.0 \\
0\end{array}$ & $\begin{array}{c}0.0 \\
0\end{array}$ & $\begin{array}{c}0.0 \\
0\end{array}$ & $\begin{array}{c}0.0 \\
0\end{array}$ & 0.27 & $\begin{array}{c}0.0 \\
0\end{array}$ & 0.00 & $\begin{array}{c}0.0 \\
0\end{array}$ & $\begin{array}{c}0.0 \\
0\end{array}$ & $\begin{array}{c}- \\
0.27\end{array}$ & 22.43 \\
\hline $\begin{array}{l}\text { y2 } \\
+\end{array}$ & 0 & 0.20 & 0.33 & 0.11 & 0.02 & 0.24 & $\begin{array}{c}0.0 \\
0\end{array}$ & $\begin{array}{c}1.0 \\
0\end{array}$ & $\begin{array}{c}0.0 \\
0\end{array}$ & $\begin{array}{c}0.0 \\
0\end{array}$ & 0.26 & $\begin{array}{c}0.0 \\
0\end{array}$ & 1.00 & $\begin{array}{c}0.0 \\
0\end{array}$ & $\begin{array}{c}0.0 \\
0\end{array}$ & 0.26 & 87.42 \\
\hline
\end{tabular}

Tabel 4. Primal Dual

\begin{tabular}{|c|c|c|c|c|c|c|c|c|c|c|c|c|c|c|c|c|c|}
\hline & & $x 1$ & $x 2$ & x3 & $x 4$ & x5 & y1+ & y2+ & y3+ & y4+ & y5+ & y1- & y2- & y3- & y4- & y5- & $\mathbf{R}$ \\
\hline & -1 & 0 & 0 & 0 & 0 & 6420.824 & 0.353423 & 0 & 2.461029 & 2.957644 & 104.7608 & 2.646577 & 5 & 2.538971 & 2.042356 & -95.7608 & -329647 \\
\hline$x 4$ & 0 & 0 & 0 & 0 & 1 & -4.64986 & -0.0003 & 0 & -0.00029 & 0.000153 & 0.002381 & 0.000298 & 0 & 0.000291 & -0.00015 & -0.00238 & 3.397653 \\
\hline y2+ & 0 & 0 & 0 & 0 & 0 & -1.24597 & -0.00011 & 1 & -0.0005 & $3.78 \mathrm{E}-05$ & 0.26211 & 0.000109 & -1 & 0.000498 & $-3.8 \mathrm{E}-05$ & -0.26211 & 76.42522 \\
\hline $\mathrm{x} 1$ & 0 & 1 & 0 & 0 & 0 & -0.47526 & $3.25 \mathrm{E}-05$ & 0 & $1.65 E-05$ & $1.01 E-05$ & -0.56632 & $-3.2 \mathrm{E}-05$ & 0 & $-1.7 \mathrm{E}-05$ & $-1 E-05$ & 0.566316 & 12.75747 \\
\hline
\end{tabular}

Fungsi tujuan mula-mula adalah fungsi tujuan minimum karena tujuannya adalah untuk meminimumkan penalti. Supaya dapat diselesaikan dengan metode simpleks maka persamaan tersebut harus diubah menjadi bentuk maksimum dengan cara mengalikan dengan negatif satu pada kedua ruas persamaan fungsi tujuan. Variabel artifisial ditambahkan pada fungsi tujuan sebagai selisih antara target dengan hasil perhitungan optimasi. Pada persamaan tersebut tidak digunakan variabel slack karena tidak ada fungsi konstrain yang berbentuk pertidaksamaan.

Seluruh persamaan yang dianalisis adalah persamaan fungsi tujuan yang memiliki target nilai. Iterasi dilakukan sampai 6 kali dan telah 
mencapai nilai optimum di mana nilai variabel non basic pada baris nol seluruhnya bernilai positif dan seluruh koefisien variabel basic pada kolom nol bernilai nol. Seluruh variabel artifisial bernilai 0 kecuali variabel y2+ yang bernilai 87,42 . Hal ini berarti bahwa penggunaan mesin oven kelebihan 87,42 jam per hari yang berarti bahwa UKM jovelyn harus menyewa oven tambahan sekitar 9 mesin oven lagi.

Langkah berikutnya adalah melakukan analisis sensitivitas terutama untuk nilai ruas kanan khusus untuk lama jam kerja atau lama penggunaan oven. Jumlah oven yang dimiliki adalah 5 oven dengan masing-masing jam operasional adalah 10 jam.

Berdasarkan hasil perhitungan, oven tersebut masih kurang sehingga perlu dilakukan analisis sensitivitas untuk menentukan penambahan jumlah oven tanpa mengubah nilai optimum. Hasil akhir iterasi menunjukkan bahwa jumlah kapasitas produksi untuk kue semprit akar kelapa, kue semprit, kue kacang dan kue nastar masingmasing adalah sebesar $12,76 \mathrm{~kg}, 16,93 \mathrm{~kg}, 3,37 \mathrm{~kg}$ dan $25,7 \mathrm{~kg}$.

\section{Kesimpulan}

Dengan metode yang digunakan maka diperoleh kapasitas produksi untuk kue semprit akar kelapa, kue semprit, kue kacang dan kue nastar masing-masing adalah sebesar $12,76 \mathrm{~kg}$, $16,93 \mathrm{~kg}, 3,37 \mathrm{~kg}$ dan $25,7 \mathrm{~kg}$.

Nilai kapasitas produksi dapat ditentukan secara akurat dan meminimumkan gap atau kesenjangan antara nilai realitas dan nilai harapan atau nilai target. Metode Goal programming dapat diterapkan untuk menentukan kapasitas produksi dengan tujuan untuk mencapai target yang dalam penelitian ini adalah target laba, target utilisasi mesin oven, target jam kerja, target jumlah bahan baku dan target utilisasi wajan pemanggangan. Goal programming memberikan selisih yang terkecil antara target dengan realisasi. Penyelesaian juga dapat dilakukan dengan mudah dan cepat dengan menggunakan variabel artifisial. Metode iterasi yang dilakukan pada goal programming sama dengan metode iterasi metode simpleks. Perbedaan yang mendasar adalah pada simpleks digunakan variabel slack sedangkan pada goal programming digunakan variabel artifisial yang merupakan variabel bebas tanpa tanda sehingga iterasi memberikan kesempatan pada variabel artifisial untuk bernilai positif atau bernilai negatif. Goal programming juga lebih efisien dibandingkan dengan big $\mathbf{M}$, karena tidak perlu menggunakan variabel artifisial yang bernilai besar. Analisis sensitivitas dapat juga dilakukan sebagai lanjutan dari iterasi goal programming. Analisis sensitivitas tidak perlu dilakukan dari matriks awal atau tabel awal melainkan dari hasil akhir iterasi goal programming. Iterasi dapat dilakukan dengan eleminasi gauss atau simpleks atau primal dual, tergantung dari letak nilai koefisien negatif

\section{Daftar Referensi}

Ali, I., Raghav, Y. S., \& Bari, A. (2011). Integer Goal programming approach for finding a compromise allocation of repairable components. International Journal of Engineering, Science and Technology, 3(6), 184-195.

Asllani, A., \& Lari, A. (2015). Using Goal Programming To Increase The Efficiency Of Marketing Campaigns. Journal of International \& Interdisciplinary Business Research Volume, 2, 1-16.

Bredström, D., Haugen, K., Olstad, A., \& Novotný, J. (2015). A mixed integer linear programming model applied in barge planning for Omya. Operations Research Perspectives, 2, 150-155. https://doi.org/10.1016/j.orp.2015.07.002

El-quliti, S. A., Hamid, A., Ragab, M., Abdelaal, R., Mohamed, A. W., Mashat, A. S., ... Altalhi, A. H. (2015). A Nonlinear Goal Programming Model for University Admission Capacity Planning with Modified Differential Evolution Algorithm. Hindawi Publishing Corporation Mathematical Problems in Engineering, 2015, 1-13.

Farzam Rad, M., \& Shirouyehzad, H. (2014). Proposing an Aggregate Production Planning Model by Goal Programming Approach, a Case Study. Data Envelopment Analysis and Decision Science, 1-13. https://doi.org/10.5899/2014/dea-00061

Hakim, M. F., Anggraeni, W., \& Pribadi, A. (2012). Optimasi Perencanaan Jumlah Base Transceiver Station (BTS) dan Kapasitas Trafik BTS Menggunakan Pendekatan Goal programming pada Sistem Telekomunikasi Seluler Berbasis GSM. Jurnal Teknik ITS, 1, $1-6$.

Hapsari, S. N., \& Rosyidi, C. N. (2017). A Goal Programming Optimization Model for The Allocation of Liquid Steel Production. IOP Conference Series: Materials Science and Engineering PAPER, 1-6. https://doi.org/10.1088/1757899X/319/1/012021

Hassan, N., Pazil, A. H. M., Idris, N. S., Razman, N. F., \& School. (2013). A Goal Programming Model for Bakery Production. Advances in Environmental Biology, 7(1) (May), 187-190.

Iwuji, A. C., \& Agwu, E. U. (2017). A Weighted Goal Programming Model for the DASH Diet Problem: Comparison with the Linear 
Programming DASH Diet Model. American Journal of Operations Research, 7, 307-322. https://doi.org/10.4236/ajor.2017.75023

Jyoti, \& Mannan, H. (2016). Goal programming: An Application To Financial Estimation Of and Organization / Institution. ELK Asia Pacific Journal Of Finance And Risk Management, 7(1), 1-15. https://doi.org/10.16962/EAPJFRM/issn.

Kumar, S., Babu, H., \& Kumar, U. (2018). Capital Budgeting Decision through Goal programming. International Journal of Engineering Research and Technology, 11(1), 65-71.

Liu, B., \& Chen, X. (2015). Uncertain Multiobjective Programming and Uncertain Goal programming. Journal of Uncertainty Analysis and Applications, 3(10), 4-11. https://doi.org/10.1186/s40467-015-0036-6

Nadar, D. K. (2016). Some Applications of Simplex Method. International Journal of Engineering Research and Reviews, 4(1), 60-63.

Orumie, U. C., \& Ebong, D. (2014). A Glorious Literature on Linear Goal Programming Algorithms. American Journal of Operations Research, 4, 59-71.

Raghavulu, P., Nynaru, V., Ch, K. P. K., \& Satya, D. A. (2016). Assessing the Effectiveness of Vendors through Goal programming using Changing Goal Priorities: Case Study. Indian Journal of Advances in Chemical Science, 146-151.

Reddy, V. K., Sunitha, S. V, \& Reddy, Y. R. (2017). Goal programming - The Means for Optimization of Sales Allocation. IOSR Journal of Mathematics (IOSR-JM), 13(2), 1-4. https://doi.org/10.9790/57281302050104

Wahyudi, A., Anwar, N., \& Edijatno. (2014). Studi Optimasi Pola Tanam pada Daerah Irigasi Warujayeng Kertosono dengan Program Linier. Jurnal Teknik ITS, 3(1), 16.

Wichapa, N., \& Khokhajaikiat, P. (2017). Solving multi-objective facility location problem using the fuzzy analytical hierarchy process and Goal programming: a case study on infectious waste disposal centers. Operations Research Perspectives, 4, 39-48. https://doi.org/10.1016/j.orp.2017.03.002

Yahia-Berrouiguet, A., \& Tissourassi, K. (2015). Application of Goal Programming Model for Allocating Time and Cost in Project Management: A Case Study From The Company of Construction Seror. Yugoslav Journal of Operations Research, 25(2), 283289.

https://doi.org/10.2298/YJOR131010010Y
Yulia, \& Singgih, M. L. (2012). Optimasi Produksi dan Distribusi di Perusahaan Gas Cair dengan Menggunakan Linear Programming dan Algoritma Cross Entropy. Jurnal Teknik ITS, 1, 557-560. 